\title{
Analysis of the influence of the variable size on the characteristics and behavior of meningiomas
}

\author{
L. Mascarenhas; M. Fonseca*; M. Honavar**; H. Romão; M. Resende and A. Rocha Vaz
}

Neurosurgery Service and **Anatomic Pathology Service. Pedro Hispano Hospital. Matosinhos. Portugal.*Mathematics Department. Sciences and Technology Faculty. Lisbon New University. Almada. Portugal.

\section{Summary}

Seventy-two patients submitted to meningioma surgery at Pedro Hispano Hospital from 1997 to 2001 were reviewed to analyze the association between size (largest diameter of the lesion obtained from imaging examinations) and other variables regarding the biological behavior and clinical outcome of these patients. Statistically significant associations were found between tumor size and location, type of first symptom, type of physical examination, histological grade, surgical complications, postoperative CSF bursae and the need for blood transfusion. Patient's age, gender, duration of first symptom, clinical status at discharge and persistent complaints were not associated to tumor size. There was a trend towards a statistically significant association between tumor size and both grade of resection and persistent deficits. The causes and implications of the findings are discussed. Tumor size is a parameter that may interfere with the neurosurgeon's capacity to treat these patients as well as with their recovery.

KEY WORDS: Meningioma. Size. Characteristics. Behavior. Correlation.

Análisis de la influencia de la variable tamaño en las características y comportamiento de los meningiomas

\section{Resumen}

Se han revisado setenta y dos enfermos sometidos a cirugía de meningioma en el Hospital Pedro Hispano entre 1997 y 2001, para evaluar la asociación entre el tamaño (mayor diámetro de la lesión obtenido a partir de los exámenes de imagen) y otras variables concernientes a la caracterización y comportamiento de la lesión. Se han encontrado asociaciones, con significación estadística, con la localización, tipo de primer síntoma, tipo de examen físico, grado histológico, aparición

Recibido: 27-01-05. Aceptado: 31-03-05 de complicaciones, bolsas de LCR y transfusiones de sangre. La edad, el sexo, la duración de primer síntoma, el estado al alta hospitalaria y los síntomas persistentes no se relacionan con el tamaño. Se encontró alguna relación con el tipo de exéresis y señales persistentes. Se discuten las causas e implicaciones de los hallazgos. El tamaño es un parámetro que puede interferir en la capacidad del neurocirujano para tratar estos pacientes y en la capacidad de recuperación de los mismos."

PALABRAS CLAVE: Meningioma. Tamaño. Características. Comportamiento. Correlación.

\section{Introduction}

Evidence based medicine has been defined as the conscientious, explicit and judicious use of current best evidence in making decisions about the care of individual patients? This should be applied to Neurosurgery as well. Current imaging methods allow for the exact size of a space-occupying lesion to be determined. Frequently empirical judgments are made based on this variable (e.g. resection of large lesions causes severe deficits, large lesions need to be embolized). The aim of the present study was to analyze the association between tumor size and some clinical variables regarding tumor behavior, surgical complications and patients' outcome.

\section{Material and methods}

The records of patients submitted to meningioma surgery at Pedro Hispano Hospital from 1997 to 2001 (5 years) were reviewed. Inclusion criteria were availability of clinical notes, imaging examinations and histological confirmation of the diagnosis. The variable size was considered as the largest diameter of the lesion in $\mathrm{mm}$ in either sagital, coronal or axial planes, obtained by direct measurement on the imaging examination films (magnetic resonance or

Abbreviations. CSF: cerebroespinal fluid. LCR: liquido cefalorraquídeo. WHO: World Healt Organization 
Table 1

Statistical association between tumor size and studied variables

\begin{tabular}{llc}
\hline Variable & \multicolumn{1}{c}{ Test } & p Value \\
\hline age & several tests & non significant \\
gender & Student's t test & 0.805 \\
location & F test (ANOVA) & 0.026 \\
duration of first symptom & F test (ANOVA) & 0.740 \\
first symptom & F test (ANOVA) & 0.003 \\
physical examination & Student's t test & 0.001 \\
histology & Mann-Whitney's test & 0.049 \\
ressection & Mann-Whitney's test & 0.116 \\
complications & Student's t test & $<0.001$ \\
CSF bursa & Mann-Whitney's test & 0.018 \\
transfusion & Mann-Whitney's test & $<0.001$ \\
state on discharge & Mann-Whitney's test & 0.906 \\
persistent complaints & Student's t test & 0.288 \\
persistent deficits & Student's t test & 0.084
\end{tabular}

Table 2

Location and mean size

\begin{tabular}{ll}
\hline & $(\mathbf{m m})$ \\
\hline parasagital & 46.75 \\
skull base & 39.24 \\
bone* & 36.00 \\
convexity & 31.10 \\
falx and tentorium & 29.88 \\
spinal & 24.50
\end{tabular}

*absent meningeal signal changes; imaging resembling fibrous osseous dysplasia

if unavailable computed tomography). For each case the following information was also obtained: gender, age at time of surgery, location of the lesion, first symptom and its duration, physical examination (normal vs. abnormal, i.e. neurological deficits and other signs either absent or present respectively), grade of resection (Simpson's grades 1, 2 and 3 vs. 4 and 5), histological grade (WHO grades 3 and 2 - malignant and atypical vs. WHO grade 1 - benign), complications (absent vs. present, if present which), state at discharge (de novo or aggravated deficits vs. same deficits or improved), follow up time, persistent complaints (absent vs. present; if present which), and persistent defi-
Table 3

First symptom and mean size

\begin{tabular}{lc}
\hline & (mm) \\
\hline higher functions impairment & 59.60 \\
seizures & 43.11 \\
motor impairment & 37.00 \\
others & 34.23 \\
pain & 31.53 \\
vision impairment & 27.40 \\
\hline
\end{tabular}

cits (absent vs. present; if present which). Complaints and deficits were considered persistent if still present at the last recorded follow up visit. Several statistical tests (summarized in table 1) were applied to the obtained results with the aid of commercially available software packages in order to look for a possible correlation with the variable size. Two types of statistical tests were used: parametric (ANOVA and Student's t test) and non-parametric (MannWhitney's test). All of these tests are used to test differences between samples. However, ANOVA and Student's t test assume normality, homoscedasticity (equal dispersion) and independence between observations, whereas MannWhitney's test merely assumes independence. When the data didn't depart too much from the parametrical tests' 


\begin{tabular}{lll}
\hline & \multicolumn{1}{c}{ Table4 } & \\
& Distribution by size \\
\hline$(\mathbf{m m})$ & $(\mathbf{n})$ & $(\mathbf{\%})$ \\
\hline$<20$ & 7 & $(10)$ \\
$>=20<40$ & 43 & $(60)$ \\
$>=40<60$ & 12 & $(17)$ \\
$>=60$ & 10 & $(14)$ \\
\hline TOTAL & 72 & 100 \\
\hline
\end{tabular}

Table 5

Distribution by location

\begin{tabular}{lrc}
\hline & (n) & $(\mathbf{\%})$ \\
\hline skull base & 21 & $(29)$ \\
convexity & 20 & $(28)$ \\
parasagital & 12 & $(17)$ \\
falx and tentorium & 8 & $(11)$ \\
spinal & 6 & $(8)$ \\
bone & 5 & $(7)$ \\
\hline TOTAL & 72 & $100 \%$ \\
\hline
\end{tabular}

Table 6

First symptom

\begin{tabular}{lcc}
\hline & $(\mathbf{n})$ & $(\mathbf{\%}) *$ \\
\hline pain & 32 & $(44)$ \\
seizures & 9 & $(13)$ \\
motor impairment & 8 & $(11)$ \\
vision impairment & 5 & $(7)$ \\
higher functions impairment & 5 & $(7)$ \\
sensory impairment & 2 & $(3)$ \\
exophtalmus & 2 & $(3)$ \\
balance impairment & 2 & $(3)$ \\
syncope & 2 & $(3)$ \\
subcutaneous mass & 2 & $(3)$ \\
speech impairment & 1 & $(1)$ \\
olfactory impairment & 1 & $(1)$ \\
tinnitus & 1 & $(1)$ \\
\hline TOTAL & 72 & $(100)$ \\
*denominator total number of patients $(\mathrm{t}=72)$ & \\
\hline
\end{tabular}

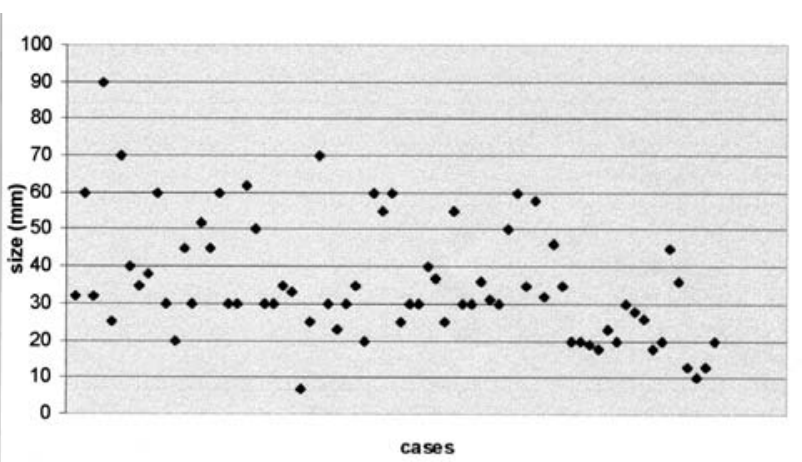

Figure 1. Illustration of the distribution by size. Each case is represented by a dot.

assumptions, these more powerful tools were used. Otherwise a non-parametric approach was called upon. Tukey's honest significant difference method is used to infer which pairs of samples in a one-way ANOVA model are statiscally different after an $\mathrm{F}$ test has turned out significant. Pairs of samples to which Tukey's method was applied are summarized in tables 2 and 3.

\section{Results}

Seventy-two patients satisfied the inclusion criteria, 20 males $(28 \%)$ and 52 females $(72 \%)$. The mean age at the time of surgery was 55.56 years (median 54.50; standard deviation 13.86; range 21-84). The distribution of the meningiomas by size is detailed in table 4 and figure 1. Their location is shown in table 5 . The first symptom and its duration are specified in tables 6 and 7 respectively. Physical examination was normal in 29 cases (40\%) and abnormal in 43 (60\%). Resection belonged to Simpson's grades 1,2 or 3 in 65 patients $(90 \%)$, and was partial (Simpson's grade 4$)$ in 7 cases $(10 \%)$. In 9 cases $(14 \%)$ the histological variety was either malignant or atypical and $63(86 \%)$ were of benign nature. In 30 patients (42\%) complications were noticed. These are detailed in table 8 . The following should perhaps be taken into account when analyzing this crude rate. Both the proportion of skull base lesions $(29 \%$, the most frequent) and of lesions of large dimension (31\% $>=40 \mathrm{~mm}$ ) may well reflect the complexity of many of the cases in the present series. Surgery of large lesions in complex areas has inherent morbidity. Nevertheless, at the time of discharge, only 13 patients (18\%) had deficits either worsened or caused by the operation. In the other $59(82 \%)$ these were either identical, improved or absent. The mean follow-up time was 30.04 months (median 29, range 1-67). Persistent complaints were referred by 6 patients $(8 \%)$; in $22(31 \%)$ persistent deficits were recorded. These are detailed in table 8 as well.

A statistically significant correlation between tumor size and location was found. Larger lesions predominated 
Table 7

Duration of first sympton

\begin{tabular}{lcc}
\hline (months) & (n) & (\%) \\
\hline$<=6$ & 28 & $(39)$ \\
$>6<=12$ & 11 & $(15)$ \\
$>12<=24$ & 9 & $(13)$ \\
$>24$ & 24 & $(33)$ \\
\hline TOTAL & 72 & $(100)$ \\
\hline
\end{tabular}

Table 8

Complications; persistent complaints and deficits

\begin{tabular}{lrr}
\hline & (n) & (\%)* \\
\hline anemia requiring blood transfusion & 10 & $(14)$ \\
CSF bursa & 10 & $(14)$ \\
cranial nerve deficit & 6 & $(8)$ \\
motor deficit (de novo/agravated) & 5 & $(7)$ \\
aphasia & 2 & $(3)$ \\
meningitis & 1 & $(1)$ \\
hydrocephalus & 1 & $(1)$ \\
CSF fistula & 1 & $(1)$ \\
intra-parenchymal hematoma & 1 & $(1)$ \\
deep venous thrombosis & 1 & $(1)$ \\
diabetes insipidus & 1 & $(1)$ \\
extra-axial hematoma & 1 & $(1)$ \\
respiratory failure & 1 & $(1)$ \\
visual field deficit & 1 & $(1)$ \\
pain & 3 & $(4)$ \\
seizures & 3 & $(4)$ \\
motor deficit & 5 & $(7)$ \\
higher functions impairment & 4 & $(6)$ \\
cranial nerve V deficit & 3 & $(4)$ \\
cranial nerve II deficit & 3 & $(4)$ \\
cranial nerve I deficit & 3 & $(4)$ \\
visual fields deficit & 3 & $(4)$ \\
cranial nerve VIII deficit & 2 & $(3)$ \\
cranial nerve VII deficit & 2 & $(3)$ \\
balance impairment & 2 & $(3)$ \\
cranial nerve XI deficit & 1 & $(1)$ \\
eye motility impairment & 1 & $(1)$ \\
dewer cranial nerves deficit & 1 & $(1)$ \\
deriorated general condition & 1 & $(1)$ \\
\hline
\end{tabular}

*denominator total number of patients $(\mathrm{t}=72)$ in skull base and parasagital locations, smaller lesions in the convexity and spine. Further analysis using Tukey's method disclosed differences between convexity and parasagital $(\mathrm{p}=0.067)$, and spinal and parasagital $(\mathrm{p}=0.052)$, although not reaching statistical significance

An association between size and the type of first symptom referred by the patient was observed. Higher functions impairment was associated with a larger mean tumor size. Using Tukey's method this difference was statistically significant when compared to almost all other symptoms: vision impairment $(\mathrm{p}=0.011)$, pain $(\mathrm{p}=0.002)$, and others $(\mathrm{p}=0.019)$. When compared to motor impairment the $\mathrm{p}$ value was 0.088 .

In patients with abnormal physical examinations the mean size of the meningioma was $40.512 \mathrm{~mm}$; in those whose examination was normal it was $28.655 \mathrm{~mm}$. Student's $t$ test confirmed the statistical significance of the difference ( $p$ value $=0.001)$. Size therefore seemed to have an influence on the type of physical examination found, the latter being more frequently abnormal in larger lesions.

The mean size of the lesion in resections of Simpson's grades $4 \& 5$ was $46.86 \mathrm{~mm}$; for grades 1,2 and 3 it was $34.54 \mathrm{~mm}$. Mann-Whitney's test gave a p value of 0.116 .

For atypical / malignant lesions the mean size found was $46.889 \mathrm{~mm}$; for those of benign nature it was $34.143 \mathrm{~mm}$. Mann Whitney's test disclosed a $p$ value of 0.049 , supporting the existence of a relation between size and histological variety. On average, atypical / malignant lesions appeared to be somewhat larger than their benign counterparts.

Patients without complications were found to have a mean size of the meningioma of $29.357 \mathrm{~mm}$, compared to those with complications who had a mean size of $44.667 \mathrm{~mm}$. The $p$ value obtained with Student's t test was $<0.001$. A role for size therefore can be inferred, larger lesions being more prone to surgical complications. Similar considerations apply to the specific cases of CSF bursa and anemia requiring blood transfusion (hemoglobin $<8 \mathrm{gL}-1$ ), Mann Whitney's test disclosing significant $p$ values $(0.018$ and $<0.001$ respectively). Patients with CSF bursa had a mean size of $49.90 \mathrm{~mm}$; those without $33.45 \mathrm{~mm}$. Transfusions were given to patients with a mean size of the lesion of $55.00 \mathrm{~mm}$. Patients not transfused had $32.63 \mathrm{~mm}$.

Patients with persistent deficits had a mean size of $40.68 \mathrm{~mm}$, those without had $33.56 \mathrm{~mm}$. Student's t test gave a $\mathrm{p}$ value of 0.084 .

\section{Discussion}

A correlation between size and a marker of proliferative potential (Ki-67 staining index), although weak, has been shown for meningiomas ${ }^{6}$. Regarding female sex hormone receptors, a tendency for tumors without progesterone receptors to have larger sizes has also been documented ${ }^{3}$. Other 
factors may correlate with size as well, and could explain why certain lesions attain huge sizes and others don't.

The predominance of these tumors in females, also seen in this study, is well known. However the hypothesis of larger tumors predominating in females is not supported by this study. No significant differences between size in males and females were found.

The hypothesis that a large tumor takes a long time to develop, possibly appearing in older patients or in patients with a long duration of first symptom, is not supported by this study either. Neither the association between tumor size and patient's age nor between tumor size and duration of the first symptom showed statistical significance.

The tolerability of a symptom, its easiness of detection, its measurability and its objectiveness, may all account for the correlation observed between size and type of first symptom. Impairment of higher functions was found to be associated with larger lesions. This particular symptom possibly causes little discomfort to the patient and family and goes unnoticed in an abbreviated examination of the mental status, thereby delaying the diagnosis and providing time for the tumor to grow.

The association found between size and location might have to do with the fact that certain locations do not admit great volumes for anatomical reasons (e.g. spine). As a lesion grows, its probability of interfering with functionally important areas obviously increases, as well as the probability of the nervous system's mechanisms of adaptation and recovery running out. This may account for the association between abnormal physical examination and larger lesions.

Histological features of malignancy correlate well with the proliferation index using the cell proliferation marker $\mathrm{Ki}-67^{6}$. Hence tumors with an increased proliferative potential would grow more rapidly and more likely achieve larger sizes. This could be related with the larger mean size of atypical / malignant lesions encountered in the present study as well.

The larger size of the meningiomas in cases where surgical complications occurred may have to do with a greater surgical aggression to the patient, namely manipulation of nervous and vascular structures. Other studies have found an association between size and edema (larger tumor, more edema) $)^{4,5}$, and between size and type of cleavage plane (larger tumor, greater difficulty in finding an extrapial plane, greater probability of having a subpial plane) $)^{1}$. Cases complicated by CSF bursae had a larger mean size. The explanation to this probably has to do with an increased probability of fistulization and consequent CSF bursa occurrence as the area requiring dural plasty enlarges. Autologous pericranial grafts were used for dural defects. Whether the development and use of synthetic materials with increased adhesiveness could decrease the incidence of this complication remains an open subject. Transfused patients harbored meningiomas with a larger mean size. The recruitment of dural and pial blood vessels during growth, thereby causing greater blood loss during resection, may account for this. Conventional microneurosurgical techniques were employed in the resection of the lesions. Pre-operative embolization was not used. This is still a matter of controversy. A significant reduction in blood loss is only achieved in lesions totally or near totally devascularized pre-operatively with this technique ${ }^{2}$, and this is not always feasible. In view of the data obtained in this study, size should probably be a criterion included in future embolization algorithms of consensus.

A greater difficulty in achieving total resection and a higher rate of persistent postoperative deficits were found when dealing with larger lesions, despite this not reaching statistical significance $(p>0.05)$. The aforementioned reasons are to be considered. However, the concept of surgical treatment of large meningiomas causing or aggravating by itself patients' deficits is not supported by the findings of the present study. Mean tumor size in patients whose deficits were caused or aggravated by surgery vs. those whose deficits were the same or improved after it, was not statiscally different. In a previous study a relation between size and outcome has been demonstrated. Statistically significant improvements in Karnofski performance scores were found for meningiomas measuring $3-6 \mathrm{~cm}^{1}$.

To conclude, the size of a meningioma may have an influence over several variables regarding the biological behavior of the tumor and the outcome of the patients. The neurosurgeon should consider tumor size as a parameter that may interfere with the capacity to surgically treat these patients as well as with their recovery.

\section{References}

1. Alvernia, J.E., Sindou, M.P.: Preoperative neuroimaging findings as a predictor of the surgical plane of cleavage: prospective study of 100 consecutive cases of intracranial meningioma. J. Neurosurg. 2004; 100: 422-430.

2. Bendszus, M., Rao, G., Burger, R., et al.: Is there a benefit of preoperative meningioma embolization? Neurosurgery 2000; 47: 1306-1312.

3. Brandis, A., Mirzai, S., Tatagiba, M., et al.: Immunohistochemical detection of female sex hormone receptors in meningiomas: correlation with clinical and histological features. Neurosurgery 1993; 33: 212-218.

4. Go, K.G., Wilmink, J.T., Molenaar, W.M.:Peritumoral brain edema associated with meningiomas. Neurosurgery 1988; 23: 175-179.

5.Lobato, R. D.,Alday, R., Gómez,P.A., etal.: Brain oedema in patients with intracranial meningioma. Correlation between clinical, radiological, and histological factors and the pre- 
sence and intensity of oedema. Acta Neurochir. 1996; 138: 485-494.

6. Nakasu, S., Nakajima, M., Matsumura, K, et al.: Meningioma: proliferating potential and clinicoradiological features. Neurosurgery 1995; 37: 1049-1055.

7. Sackett, D.L., Straus, S.E., Richardson, W.S., et al.: Evidence based medicine. How to practice and teach EBM. $2^{\text {nd }}$ ed. London: Churchill Livingstone, 2000; pp. 1-280.
Mascarenhas, L.; Fonseca, M.; Honavar, M.; Romão, H.; Resende, M.; Rocha Vaz, A.: Analysis of the influence of the variable size on the characteristics and behavior of meningiomas. Neurocirugía 2005; 16: 486-491.

Correspondence postal: Dr. Lino Mascarenhas. Serviço de Neurocirurgia. Hospital Pedro Hispano. Rua Dr. Eduardo Torres. 4454509 Matosinhos. Portugal. 